\title{
ENHANCEMENT OF THE SOLUBILITY OF FAMOTIDINE SOLID DISPERSION USING NATURAL POLYMER BY SOLVENT EVAPORATION
}

\author{
HUSSEIN K. ALKUFI ${ }^{*}$, ASMAA M. RASHID ${ }^{2}$
}

${ }^{1}$ Department of Pharmacognacy, College of Pharmacy, Thi-Qar University, Thi-Qar, Iraq, ${ }^{2}$ Collage of Pharmacy, Uruk University, Baghdad, Iraq Email: husseinalkufi21@utq.edu.iq

Received: 30 Jan 2021, Revised and Accepted: 05 Apr 2021

\begin{abstract}
Objective: The aims of the study to enhance solubility and dissolution of famotidine using natural polymer. Solubility study of a drug is one of the contributing factors of its oral bioavailability. The formulation of poorly soluble drugs for oral delivery presents a challenge to the formulatio $\mathrm{n}$ technologists.

Methods: The present study has shown that it is possible to raise the solubility for poorly soluble drugs like famotidine, by preparing solid dispersion using natural water-soluble polymer (xyloglucan and hyaluronic acid) as solubilizer through solvent evaporation method. Physical mixture and solid dispersion of famotidine with xyloglucan (XG) or hyaluronic acid in a ratio of 1:1, 1:2, 1:3 were prepared. Solubility study, drug content, dissolution profile and compatibility study were performed for famotidine in solid dispersions XS1, XS2, XS3, HS4, HS5, HS6 as well as in physical mixtures at a ratio 1:1 for both polymer (XG and hyaluronic acid).
\end{abstract}

Results: It was observed that solid dispersions of each drugs showed an increase in dissolution rate in comparison with its pure drug in the ratio of 1:1 (Drug: carrier). It can be concluded that with the care and proper use of xyloglucan, the solubility of drugs poorly soluble can be improved.

The prepared solid dispersion showed improvement of drug solubility in all prepared formulas. The best result was obtained with formula XS1 (famotidine: xyloglucan at ratio 1:1) that showed 26 fold increase in solubility compared to the solubility of pure drug

Conclusion: The natural solid dispersion, increased wettability and reduced crystallinity of the drug which leads to improving solubility and dissolution.

Keywords: Famotidine, Glacial acetic acid, Physical mixture, Solid dispersion, Solvent evaporation, Xyloglucan, Hyaluronic acid

(C) 2021 The Authors. Published by Innovare Academic Sciences Pvt Ltd. This is an open access article under the CC BY license (https://creativecommons.org/licenses/by/4.0/) DOI: https://dx.doi.org/10.22159/ijap.2021v13i3.40934. Journal homepage: https://innovareacademics.in/journals/index.php/ijap

\section{INTRODUCTION}

Therapeutic efficacy of a drug-related to the bioavailability and finally upon the solubility of drug particles. Solubility performance of a drug substance is one of the key factors of its oral bioavailability. In current years, the list of drug poorly soluble applicants has increased hugely. The poorly soluble drugs formulation for oral transport presents an experiment to the formulation researchers. The rate and extent of absorption the drug from any dosage form depend on the rate and extent of dissolution of the active ingredient [1]

The various method responsible for increase solubility and the dissolution rate of poorly soluble drugs such as liquisolid, in which inert carrier's molecules is loaded with drug particles [1]. Increase wettability and solubility of the hydrophobic drug by numerous surfactants at different charges [2]. Another method i.e. drug micronization is inappropriate method because after micronization the product has been agglomerated. The solid dispersion by natural polymer is also one of the procedure to formulate solid dispersions because of its simplicity of preparation, more effective, not require instruments more expensive and ease of optimization [3]. In solid dispersion method, whereby the active drug were dispersed in natural polymer, typically with a view to enhancing solubility, dissolution rate and oral bioavailability [4].

Xyloglucan (XG) is a biodegradable polysaccharide extracted from Tamarind seeds has been found to have an extensive application in the pharmaceutical industry [5]. However, hyaluronic acid a naturally polymer, besides being biodegradable, showed to be highly biocompatible [6].

Famotidine is classified into Class II based on Biopharmaceutics Classification System, having a low solubility and high permeability. Strongly act on $\mathrm{H} 2$ receptors, reduced acid secretion and it protect mucosal acid secretions for 10-12 $\mathrm{h}$ then metabolized and elimination by renal route. Famotidine freely soluble in glacial acetic acid [7]. Famotidine also decrease both basal, food-stimulated acid secretion by $90 \%$ as well as promotes healing of duodenal ulcer [8].
With Molecular Formula: C8H15N702S3 and Its structural formula is shown in fig. 1<smiles>NC(N)=Nc1nc(CSCC/C(N)=N/S(N)(=O)=O)cs1</smiles>

Fig. 1: Chemical structure of famotidine

This drug is BCS class II drug having low solubility. Therefore, it needs to formulate into its novel form for solubility enhancement [9]. In this study, novel solid dispersion was prepared using XG or hyaluronic acid as hydrophilic natural carrier. The dissolution of drug from natural solid dispersion formulation were examined in phosphate buffer $\mathrm{pH}$ 4.5. The aim this work was to design, prepare and evaluate natural solid dispersions of famotidine with XG or hyaluronic acid using solvent evaporation method for solubility enhancement of famotidine.

\section{MATERIALS AND METHODS}

\section{Material}

Xyloglucan and hyaluronic acid was purchased from Hyperchem(China) Potassium dihydrogen phosphate was purchased from Thomas Baker, India. Famotidine was provided by (Samarra Drug Industry, Iraq) Substance and reagent used were all of analytical grade.

\section{Characterization of famotidine}

\section{Melting point}

Determining the melting point of famotidine was according to the method stated by the USP. First, a glass capillary tube charged, one end of which is sealed, with a enough amount of dry powder to form a column in the bottom of tube 2.5 to $3.5 \mathrm{~mm}$ high when packed 
down as closely as possible by enough tapping on a solid surface. Then these packed capillary tubes placed in electrical melting point apparatus and start heating with monitoring until complete melting of powder [10].

\section{Determination of $\lambda$ max}

Twenty milligrams of famotidine were dispersed in $100 \mathrm{ml} 0.1 \mathrm{~N}$ phosphate buffer $\mathrm{pH}$ 4.5(prepared by dissolving $13.6 \mathrm{~g}$. of monobasic potassium phosphate in $1 \mathrm{~L}$ distilled water) [10] to prepare $0.2 \mathrm{mg} / \mathrm{ml}$ stock solution. From this stock solution, a dilute solution $(20 \mu \mathrm{g} / \mathrm{ml})$ was prepared and scanned by UV spectrophotometer at the range of $200-400 \mathrm{~nm}$ to obtain the $\lambda$ max of famotidine in this media.

Same procedure was used for the determination of $\lambda$ max of famotidine in water, by using water as a solvent instead of $0.1 \mathrm{~N}$ phosphate buffer $\mathrm{pH} 4.5$

\section{Preparation of calibration curves}

Calibration curves of famotidine in $0.1 \mathrm{~N}$ phosphate buffer $(\mathrm{pH} 4.5$ ) and distilled water were constructed by preparing serial dilutions of the drug from $0.2 \mathrm{mg} / \mathrm{ml}$ stock solution for each medium. The prepared samples were analyzed spectrophotometrically for famotidine at its $\lambda$ max in both mediums. The determined absorbance values were plotted versus the concentration.

\section{Determination of saturated solubility in water}

Saturation solubility studies were carried out using distilled water as a solvent using theshake-flask method. Excess amount of famotidine pure powder was taken and added to water $(10 \mathrm{ml})$ with continuous shaking for $48 \mathrm{~h}$ at $25^{\circ} \mathrm{C}$. The sample was then taken and filtered by using Millipore filter paper $0.45 \mu \mathrm{m}$. The filtrate was suitably diluted with distilled water and analyzed at the specified $\lambda$ max to determine the dissolved quantity of famotidine [11].

\section{Methods}

\section{Preparation of physical mixture}

Physical mixture (PM) of famotidine with natural polymer (XG or hyaluronic acid) was prepared at ratio of $1: 1(\mathrm{w} / \mathrm{w})$ as shown in table 1 . The mixture was mixed homogeneously, stored in a sealed container and kept in a desiccators [12].

\section{Preparation of solid dispersion}

Natural solid dispersions of famotidine were prepared by solvent evaporation method using natural polymers like XG and hyaluronic acid as carriers in 1:1,1:2 and 1: 3 ratios as shown in table 1 . Famotidine was dissolved in glacial acetic acid to get clear solution. XG or hyaluronic acid were dispersed as fine particles and the solvent was removed by evaporation at room temperature. The dried mass was stored in desiccator until constant mass was obtained, crushed, and passed through sieve no. $22[12,13]$.

Table 1: Composition of solid dispersion

\begin{tabular}{lll}
\hline Formula code & Polymer & $\begin{array}{l}\text { Drug: polymer } \\
\text { ratio }\end{array}$ \\
\hline XS1 & Xyloglucan & $1: 1$ \\
XS2 & & $1: 2$ \\
XS3 & & $1: 3$ \\
PM1 & $1: 1$ \\
HS4 & $1: 1$ \\
HS5 & Hyaluronic acid & $1: 2$ \\
HS6 & & $1: 3$ \\
PM2 & & $1: 1$ \\
\hline
\end{tabular}

\section{Characterization of solid dispersion and physical mixture}

\section{Calculation of percentage yield}

The percentage yields were calculated to determine the efficiency of the methods which were used for the preparation of binary systems and it helps in the choice of appropriate method of production. The prepared natural solid dispersion were weighed after drying, and percentage yield was calculated as in the following equation [14].

$$
\text { Percentage yield }=\frac{\text { Actual weight of the prepared granules }}{\text { Weight of drug }+ \text { polymer }} \times 100
$$

\section{Drug content}

The powder equivalent to $20 \mathrm{mg}$ famotidine was weighed and transferred to $100 \mathrm{ml}$ volumetric flask and volume was made up to the mark with $0.1 \mathrm{~N} \mathrm{KH} 2 \mathrm{PO} 4$ buffer. From this $1 \mathrm{ml}$ was taken in 10 $\mathrm{ml}$ volumetric flask and the volume was adjusted up to the mark with buffer. After sufficient dilution with $0.1 \mathrm{~N}$ KH2PO4 buffer, samples were analyzed for famotidine spectrophotometrically at its $\lambda$ max. Famotidine content was calculated by comparison the obtained absorbance with the calibration curve [15].

\section{Saturation solubility test}

To evaluate the increase in solubility of famotidine in Solid dispersions XS1, XS2, XS3, HS4, HS5, HS6 as well as in Physical mixtures PM1, PM2. Excess of formulations were added to $10 \mathrm{ml}$ of distilled water taken in a stoppered conical flasks were shaken for $48 \mathrm{~h}$ at $25{ }^{\circ} \mathrm{C}$ in incubator shaker. after shaking to achieve equilibrium, $5 \mathrm{ml}$ aliquots were withdrawn and filtered through using millipore filter paper $0.45 \mu \mathrm{m}$. The filtrate was analysed spectrophotometrically [16] at $\lambda \max .280 \mathrm{~nm}$. Readings were taken in triplicate and observations are recorded.

\section{Selection of the best formula}

The best natural solid dispersion formula is to be selected depending on the results of percentage yield and solubility and subjected for further studies.

\section{In vitro dissolution study}

An amount equivalent to $20 \mathrm{mg}$ of pure drug, accepted solid dispersion or its corresponding physical mixture was placed in dissolution apparatus type II (Paddle) at the rotation speed of 50 rpm using $900 \mathrm{ml}$ of $0.1 \mathrm{~N} \mathrm{PH} 4.5 \mathrm{KH} 2 \mathrm{PO} 4$ buffer as dissolution media at $37 \pm 0.5{ }^{\circ} \mathrm{C}$. After fixed time intervals $5 \mathrm{ml}$ of sample was withdrawn and replaced by equal volume of fresh medium, to maintain sink condition. These samples were analyzed using UVVisible Spectrophotometer at famotidine $\lambda \max [10]$

\section{Compatibility study}

\section{Differential scanning calorimetry (DSC)}

Thermal properties of the pure drug, selected formula (XS1) and its corresponding physical mixture (PM1) were analyzed by DSC using aluminum pan with about $2 \mathrm{mg}$ of the above samples.

The samples were heated in a hermetically sealed aluminum pan. Heat runs for each sample were set from $25{ }^{\circ} \mathrm{C}$ to $300{ }^{\circ} \mathrm{C}$ under dynamic $\mathrm{N} 2$ atmosphere and heating rate of $10^{\circ} \mathrm{C} / \mathrm{min}$ [17].

\section{Statistical analysis}

The results of the research were given as mean values \pm standard deviation (SD) and examined according to the one-way analysis of variance (ANOVA) at which significant results $(\mathrm{p}<0.05)$ and nonsignificant $(p>0.05)$.

\section{RESULTS AND DISCUSSION \\ Characterization of famotidine}

Determination of melting point

The melting point of famotidine was found to be $164{ }^{\circ} \mathrm{C}$. This result was within the reported range which is 163 to $164{ }^{\circ} \mathrm{C}[18]$. This indicates the purity of drug powder.

\section{Determination of $\lambda$ max}

The wave lengths of maximum absorbance ( $\lambda$ max) for famotidine in $0.1 \mathrm{~N}$ phosphate buffer $\mathrm{pH} 4.5$ and in distilled water were $266 \mathrm{~nm}$ and $280 \mathrm{~nm}$ respectively as shown in fig. 2 and fig. 3 respectively which were in agreement with the reported results $[18,19]$. 


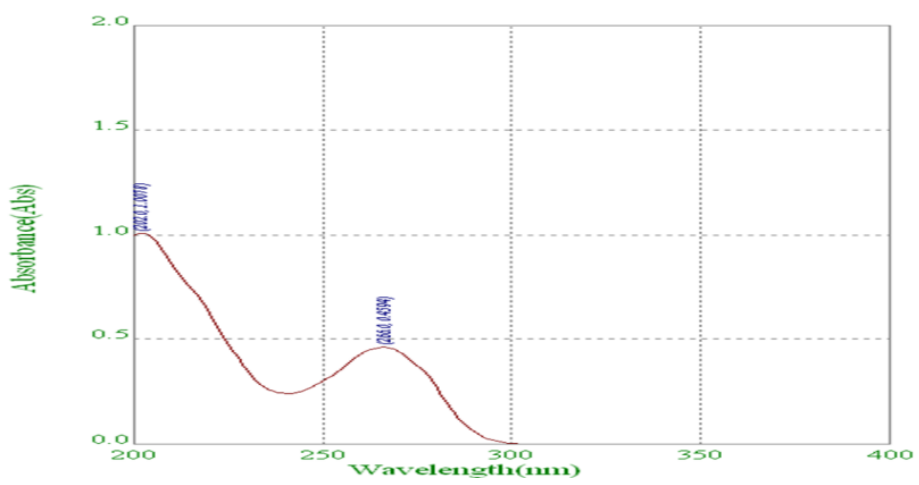

Fig. 2: UV spectrum of famotidine in phosphate buffer (pH 4.5)

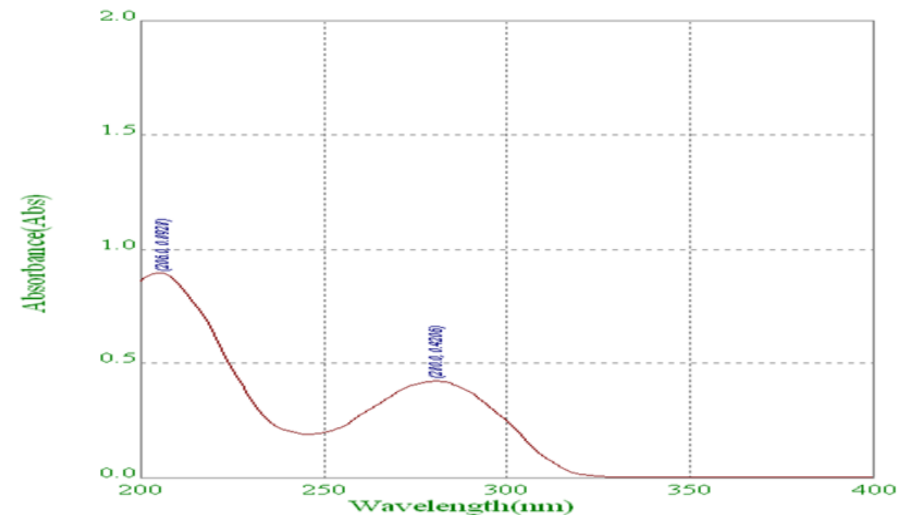

Fig. 3: UV spectrum of famotidine in distilled water

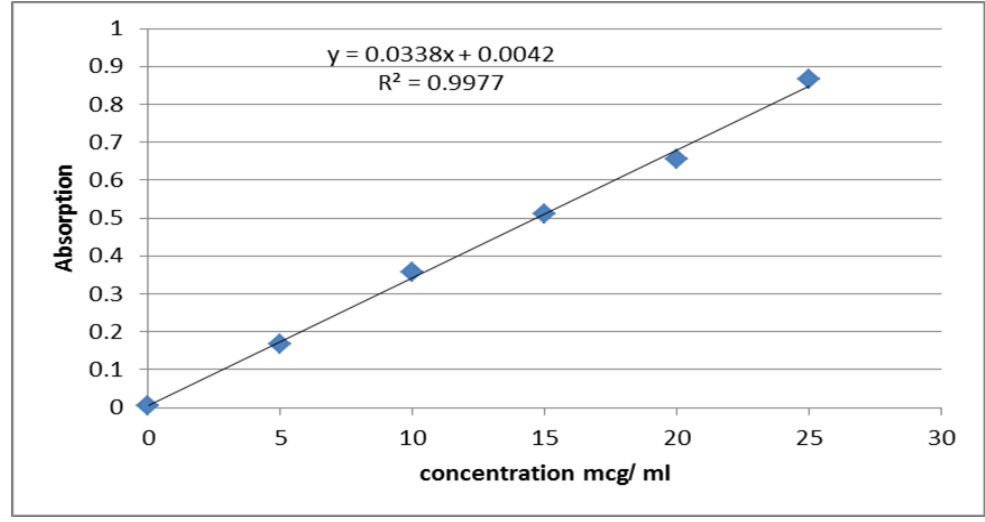

Fig. 4: Calibration curve of famotidine in $0.1 \mathrm{M}$ phosphate buffer (pH 4.5)

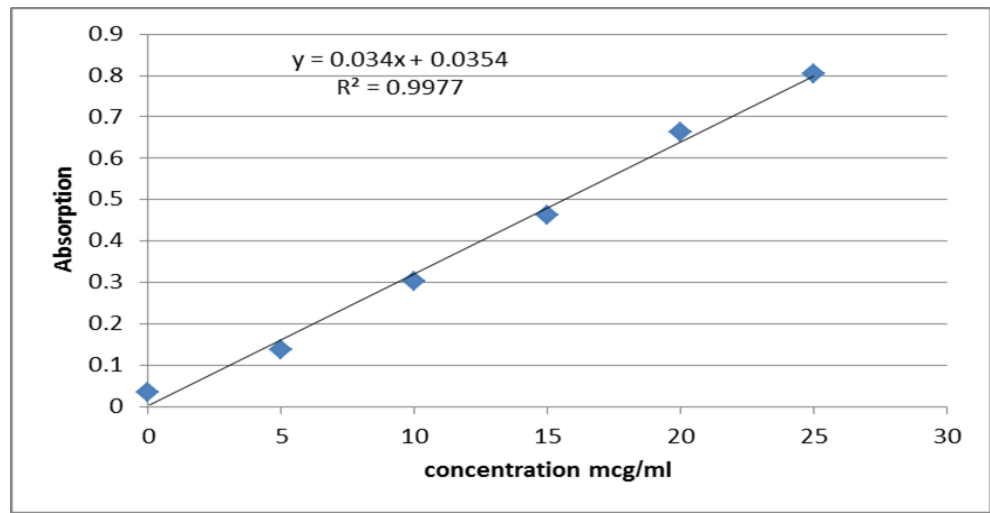

Fig. 5: Calibration curve of famotidine in distilled water 
Calibration curve of famotidine in $0.1 \mathrm{~N}$ phosphate buffer $\mathrm{pH} 4.5$ and distilled water

Calibration curves of famotidine in $0.1 \mathrm{~N}$ phosphate buffer $\mathrm{pH} 4.5$ and distilled water are represented in fig. 4 and fig. 5 . The curves were linear at the concentration range of $5-20 \mu \mathrm{g} / \mathrm{ml}$ with regression values of 0.9959 and 0.9977 respectively. The high regression values indicate that the calibration curves follow Beer's law.

\section{Determination of saturated solubility in water}

The saturated solubility of famotidine in water was found to be equal to $0.405 \mathrm{mcg} / \mathrm{ml}$, This indicated that the drug is very slightly soluble in water as mentioned in BP [20].

\section{Characterization of melt granules and physical mixture}

\section{Percentage yield}

The percentage yield of the prepared natural solid dispersion and physical mixture is shown in table 2. High percentage yield was obtained in the case of drug: polymer ratio of 1:1 in comparison to a ratio of $1: 2$ and 1:3 due to less stickiness of the resulted mass with ease penetration through the sieve.

\section{Drug content}

The percentage of drug content of the prepared natural solid dispersion and physical mixture is shown in table 2 . All formulations had drug content values within the range of $88.7-100 \%$.

\section{Solubility}

The saturation solubility of pure drug, prepared natural solid dispersion and physical mixture is shown in table 2 . The solubility of prepared solid dispersion was improved compared to pure drug powder and physical mixtures. The improvement insolubility of the solid dispersion can be explained to be due to the hydrophilic nature of the used polymers that adsorbed on drug surface [21] and improve its wettability, so the solubility was improved [22].

\section{Selection of the formula}

Depending on the solubility and Percentage yield results, xyloglucan at ratio 1:1 was the best polymer for enhancing the solubility of famotidine. So XS1 is the best-selected formula for further studies.

\section{In vitro dissolution studies}

The in vitro dissolution profiles of the pure drug, XS1 and its corresponding physical mixture in phosphate buffer $\mathrm{pH} 4.5$ for 30 min are shown in fig. 6. The dissolution of pure drug was rather slow. Since, the cumulative amount of dissolved drug after $5 \mathrm{~min}$. was about $24 \%$, while XS1 formulation showed the greatest amount of drug release, about $80.7 \%$ within 5 min.

The dissolution rate of the physical mixture was improved as compared with pure drug, but to a lesser extent than that of the solid dispersion, this might be due to the surface tension lowering effect of polymer to the medium, resulting in wetting of hydrophobic drug of crystalline surface [23]. The fastest dissolution of XS1 is due to its dispersion in the hydrophilic polymer (XG).

Table 2: Percentage yield, drug content and solubility of the prepared solid dispersion

\begin{tabular}{|c|c|c|c|c|c|}
\hline Formula code & Polymer & $\begin{array}{l}\text { Drug: polymer } \\
\text { ratio }\end{array}$ & $\begin{array}{l}\text { Drug content } \\
(\%) \pm \mathrm{SD}^{*}\end{array}$ & $\begin{array}{l}\text { Yield } \\
(\%) \pm S D^{*}\end{array}$ & $\begin{array}{l}\text { Saturation solubility } \\
(\mathrm{mg} / \mathrm{ml}) \pm \mathrm{SD}^{*}\end{array}$ \\
\hline Pure drug & -------- & $1: 0$ & $100 \pm 0.00$ & $100 \pm 0.00$ & $0.405 \pm 0.002$ \\
\hline $\mathrm{XS1}$ & & $1: 1$ & $97.7 \pm 1.53$ & $98 \pm 0.00$ & $10.436 \pm 0.045$ \\
\hline XS2 & $X G$ & $1: 2$ & $91.3 \pm 1.15$ & $91 \pm 1.00$ & $6.368 \pm 0.326$ \\
\hline XS3 & & $1: 3$ & $98.7 \pm 0.58$ & $94.6 \pm 1.52$ & $4.487 \pm 0.251$ \\
\hline PM1 & & $1: 1$ & $100 \pm 0.00$ & $99.7 \pm 0.58$ & $1.073 \pm 0.011$ \\
\hline HS4 & & $1: 1$ & $95.7 \pm 0.58$ & $78.3 \pm 2.08$ & $1.276 \pm 0.009$ \\
\hline HS5 & Hyaluronic acid & $1: 2$ & $88 \pm 1.00$ & $87 \pm 1.00$ & $1.187 \pm 0.012$ \\
\hline HS6 & & $1: 3$ & $91 \pm 0.00$ & $90.7 \pm 0.58$ & $0.882 \pm 0.017$ \\
\hline PM2 & & $1: 1$ & $100 \pm 0.00$ & $99 \pm 1.00$ & $0.931 \pm 0.010$ \\
\hline
\end{tabular}

*mean \pm standard deviation (SD), $\mathrm{n}=3$

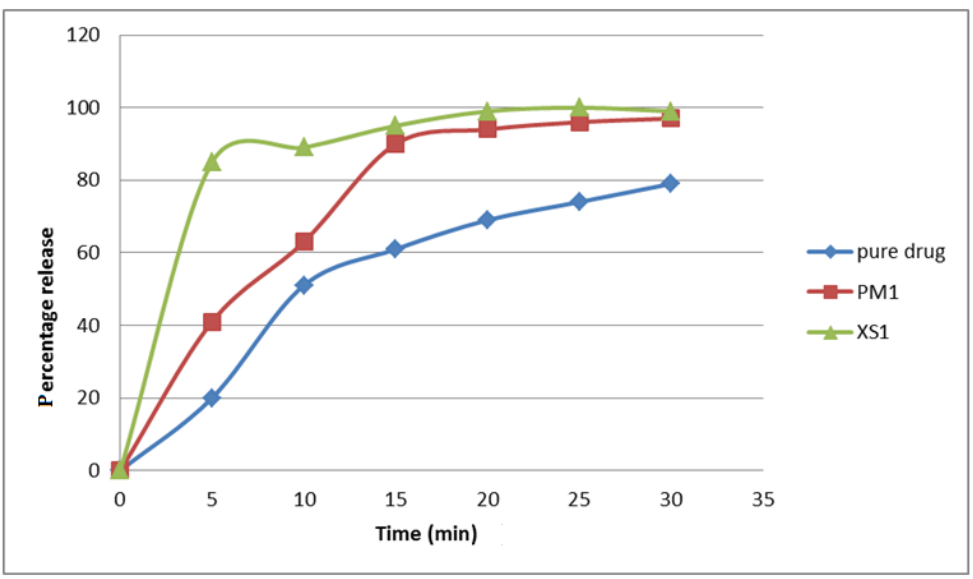

Fig. 6: Drug release profiles of pure drug, melt granules and physical mixture

\section{Compatibility study}

\section{Differential scanning calorimetry (DSC)}

The DSC thermograms of famotidine, xyloglucan, physical mixture and nature solid dispersion (XS1) are illustrated in (fig. 7 A through D). Pure drug and polymer showed sharp endothermic peak at $162.21{ }^{\circ} \mathrm{C}$ and $176.47^{\circ} \mathrm{C}$ respectively [24] which were attributed to their melting points indicating the purity and the crystalline nature of each. Physical mixture showed peaks for both components at nearly the same melting point for each indicating no interaction between them. In addition, the thermogram for the selected granules also showed the sharp endothermic peaks with no great change in the melting point of 
each component, indicating that, the crystalline nature was preserved during the granulation process. This result was in agreement with that with previous results. So it may be concluded, that the increase in solubility of the drug was mainly due to wetting of drug by its dispersion in the hydrophilic polymer (xyloglucan) rather than its conversion from crystalline form to amorphous form [25].
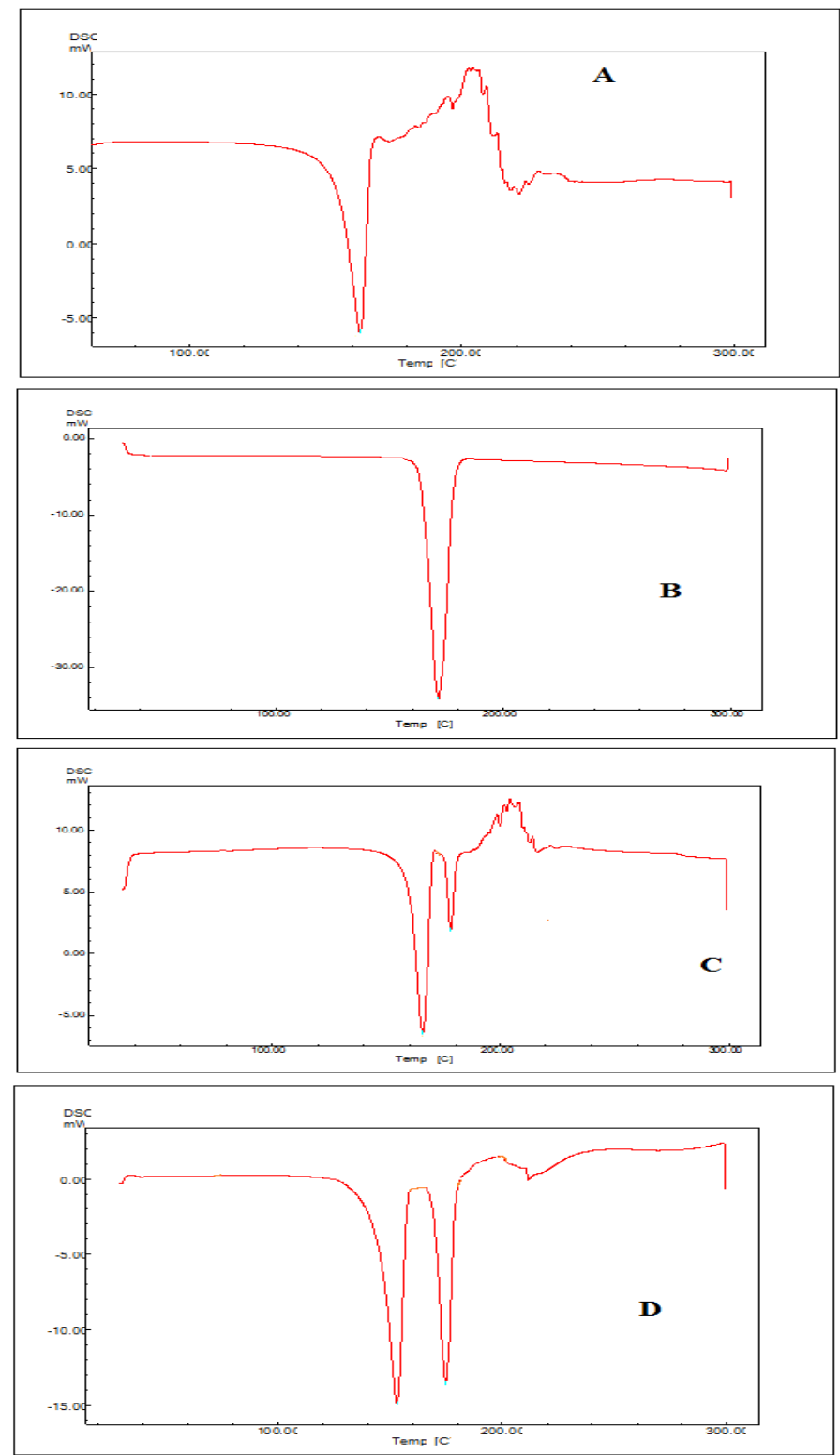

Fig. 7: DSC Thermograms of (A) famotidine, (B) xyloglucan(C) physical mixture,(D) natural solid dispersion

\section{CONCLUSION}

Depending on the obtained result of this study, solid dispersion has been proved to be a viable process to enhance solubility and dissolution rate of famotidine, using a hydrophilic natural polymer as nature polymer xyloglucan. Nature polymers like xyloglucan and hyaluronic acid were found to have a positive effect on solubility. The drug: polymer ratio, in addition to polymer type, affect the solubility of the drug. The optimum ratio of drug: xyloglucan was (1:1) with doubling in saturated solubility of the drug. Analysis by DSC of granules of selected formula indicated the preservation of the crystallinity of the drug.

\section{FUNDING}

Nil

\section{AUTHORS CONTRIBUTIONS}

All authors have contributed equally.

\section{CONFLICT OF INTERESTS}

Declared none

\section{REFERENCES}

1. Arunachalam A, Karthikeyan M, Konam K, Prasad PH, Sethuraman S, Ashutoshkumar S. Solid dispersions: a review. JCPR 2010;1:82-90.

2. Bakatselou V, Oppenheim RC, Dressman JB. Solubilization and wetting effects of bile salts on the dissolution of steroids. Pharma Res 1991;8:1461-9.

3. Chiou WL, Riegelman S. Pharmaceutical applications of solid dispersion systems. J Pharma Sci 1971;60:1281-302.

4. Noyes AA, Whitney WR. The rate of solution of solid substances in their own solutions. J Am Chem Soc 1897;19:930-4.

5. Anamika S, Shikha A. Solubility enhancement potential of tamarind seed polysaccharide as a pharmaceutical excipient. Int J Pharma Biol Arch 2012;3:456-59. 
6. Alkufi HK, Kassab HJ. Formulation and evaluation of sustained release sumatriptan mucoadhesive intranasal in-situ gel. Iraqi J Pharma Sci 2019;28:95-104.

7. Shafique M, Khan MA, Khan WS, Ahmad W, Khan S. Fabrication, characterization, and in vivo evaluation of famotidine loaded solid lipid nanoparticles for boosting oral bioavailability. J Nanomaterials 2017;1:2017.

8. Verma U, Naik JB, Mokale VJ. Preparation and characterisation of the inclusion complex of famotidine with (2-Hydroxy Propyl)- $\beta$ cyclodextrin and PVP K-30: effects on solubility and bitter taste mask. Int Conf Adv Chem Eng Technol 2014;63:2-67.

9. Uddin R, Ali F, Biswas SK. Water solubility enhancement of atorvastatin by solid dispersion method. Stamford J Pharma Sci 2010;3:43-6.

10. USP29-NF24, UPJR MD. US Pharmacopoeial Convention; 2006.

11. Jouyban A. Handbook of solubility data for pharmaceuticals. Crc Press; 2009

12. Das A, Nayak AK, Mohanty B, Panda S. Solubility and dissolution enhancement of etoricoxib by solid dispersion technique using sugar carriers. Inter Scholarly Res Notices 2011. DOI:10.5402/2011/819765

13. Shete AS, Yadav AV, Murthy SM. Chitosan and chitosan chlorhydrate based various approaches for enhancement of dissolution rate of carvedilol. DARU J Pharma Sci 2012;20:1-9.

14. Afifi S. Solid dispersion approach improving dissolution rate of stiripentol: a novel antiepileptic drug. Iranian J Pharma Res IJPR 2015;14:1001-14.

15. Jaimini M, Rana AC, Tanwar YS. Formulation and evaluation of famotidine floating tablets. Curr D Del 2007;4:51-5.

16. Bhide P, Nachinolkar R. Formulation development and characterisation of meclizine hydrochloride fast dissolving tablets using solid dispersion technique. Int J Appl Pharma 2018;7:141-6.

17. Vimalson DC, Parimalakrishnan S, Jeganathan NS, Anbazhagan S. Solid dispersion technique to enhance the solubility and dissolution of febuxostat an BCS class II drug. Int J Appl Pharm 2019;11:241-6.

18. Moffat AC, Osselton MD, Widdop B, Watts J. Clarke's analysis of drugs and poisons. London: Pharmaceutical Press; 2011.

19. Mohite MT, Shet S, Shaikh S, Aaidya V, Karodi R. Analytical method development of famotidine USP in bulk and single component formulation. Int J Res Ayurveda Pharm 2010;1:4759.

20. Cartwright AC. The British pharmacopoeia, 1864 to medicines, International Standards and the State; 2014.

21. Kalra K, Sharma S, Jain DA. Enhancement of solubility and dissolution rate of rifapentine by melt granulation technique. Int J Pharm Life Sci 2012;3:1503-6.

22. Sarada A, Lohithasu D, Chamundeswari V, Midhun Kumar D, Ramya S. Enhancement of dissolution rate of ritonavir: a comparative study using various carriers and techniques. Global J Pharm 2015;9:326-40.

23. Sharma A, Jain CP, Tanwar YS. Preparation and characterization of solid dispersions of carvedilol with poloxamer 188. J Chilean Chem Soc 2013;58:1553-7.

24. Farias MD, Albuquerque PB, Soares PA, de Sa DM, Vicente AA, Carneiro-da-Cunha MG. Xyloglucan from hymenaea courbaril var. courbaril seeds as encapsulating agent of L-ascorbic acid. Int J Biol Macromol 2018;107:1559-66.

25. Sharma A. Preparation and characterization of solid dispersions of valsartan with poloxamer 188. Der Pharm Lett 2010;2:54-63 